\title{
ESTUDO DA LAMA VERMELHA COMO MEIO DE REAÇÃO FENTON NO TRATAMENTO DE EFLUENTES DA INDÚSTRIA TEXTIL
}

\author{
F. P. ARAUJO ${ }^{1}$, F. L. NAVES ${ }^{1}$ e V. M. M. VIEIRA ${ }^{1}$ \\ ${ }^{1}$ Universidade Federal de São João del Rei, Departamento de Engenharia Química \\ E-mail para contato: flavia3ap9@yahoo.com.br
}

\begin{abstract}
RESUMO - Pelo trabalho avaliou-se a ativação térmica e química da lama vermelha, resíduo do processo Bayer de obtenção de alumina, para ser usada como meio de reação Fenton no tratamento de efluentes têxteis. Da amostra recebida e seca, foram separadas alíquotas, as quais receberam tratamentos distintos, variando-se volume de solução de $\mathrm{H}_{2} \mathrm{O}_{2}$, tempo de agitação, temperatura de calcinação e $\mathrm{pH}$ do meio. Após sua ativação, cada amostra foi empacotada em um tubo, formando uma coluna por onde percolou uma solução de corante azul de metileno, análogo ao efluente têxtil. Verificou-se a eficiência da remoção do corante através de análise em espectrofotômetro de UV visível da solução contendo o corante antes e após passar pela coluna de lama vermelha. Através dos resultados obtidos, determinou-se os valores de melhor eficiência de remoção para cada umas das variáveis trabalhadas, demonstrando que o método é uma boa alternativa para o tratamento de efluentes têxteis e aproveitamento da lama vermelha.
\end{abstract}

\section{INTRODUÇÃO}

O alumínio é o terceiro elemento mais abundante da crosta terrestre e sua produção mundial, atualmente, supera a soma de todos os outros metais não ferrosos. A ele são dadas inúmeras aplicações em diversos setores industriais: automobilístico, construção civil, eletroeletrônico, petroquímico, aeroespacial, embalagens e etc. O minério utilizado para a obtenção do alumínio metálico é a bauxita, sendo ela constituída essencialmente por várias espécies de hidróxido de alumínio e algumas impurezas de ferro e silício (Figueiredo, 2000).

O Brasil possui a terceira maior reserva de bauxita do mundo (10\% das reservas mundiais) perdendo apenas para Guiné (25\%) e Austrália (23\%). As reservas brasileiras somam 3,4 bilhões de toneladas e sua produção anual é de 26 milhões de tonelada/ano (Martines, 2009).

O alumínio é produzido a partir da alumina, sendo esta, extraída da bauxita pelo Processo Bayer. O Processo Bayer se utiliza da propriedade dos hidróxidos de alumínio presentes na bauxita se dissolverem em solução de hidróxido de sódio. Nesse processo, as espécies que contém alumínio são dissolvidas formando um licor verde que é utilizado na produção de alumina. Os resíduos de óxidos 
de ferro e outros compostos presentes na bauxita são separados, gerando um resíduo insolúvel, altamente alcalino, denominado lama vermelha (red mud).

A quantidade de lama vermelha gerada pode chegar ao dobro da quantidade de alumina produzida. Dados da literatura mostram que uma variação entre 0,3 e 2,5 toneladas de lama vermelha são geradas a cada tonelada de alumina produzida (Wang et al, 2008).

Estudos realizados com a lama vermelha sobre corrosividade, reatividade e toxidade não a classificam como um resíduo perigoso, entretanto, devido a sua elevada alcalinidade, a sua disposição precisa ser feita em locais adequados, como lagoas de disposição, construídas com técnicas de elevado custo, que impossibilitem a ocorrência de lixiviação de seus componentes e a consequente contaminação dos corpos d'água da superfície e das águas subterrâneas (Wang et al, 2008).

A quantidade de lama vermelha produzida é muito grande, e a sua disposição deve prever uma grande área contribuindo assim como custo adicional e permanente ao processo de produção do alumínio. Sua disposição inadequada pode acarretar também diversos problemas ambientais, como por exemplo, a contaminação da água superficial e subterrânea por $\mathrm{NaOH}$, ferro, alumínio ou outro agente químico e o vento pode carrear pó dos depósitos de lama vermelha seca, formando nuvens de poeira alcalina.

Os custos econômicos e os riscos ambientais associados à disposição da lama vermelha têm motivado companhias e pesquisadores na busca por alternativas ambientalmente mais seguras, que possibilitem a redução do volume de resíduo encaminhado para a disposição final. Uma alternativa para os problemas causados pela enorme produção de lama vermelha é o desenvolvimento de tecnologias que visem a sua reutilização. No presente trabalho a lama vermelha será reutilizada no setor da indústria têxtil para o tratamento de efluentes líquidos através da reação Fenton.

\section{OBJETIVO}

Ativar a lama vermelha por meio de tratamento térmico e químico, possibilitando conhecer o potencial da lama vermelha para o tratamento de efluentes.

\section{MATERIAIS E MÉTODOS}

\subsection{Coluna de empacotamento da lama vermelha}

Para a realização dos experimentos, foi usada uma coluna de vidro, apresentada na Figura 1. A coluna apresenta diâmetro de $0,5 \mathrm{~cm}$ e comprimento de $13 \mathrm{~cm}$. À sua base foi colocado um suporte de algodão para conter a lama vermelha. 


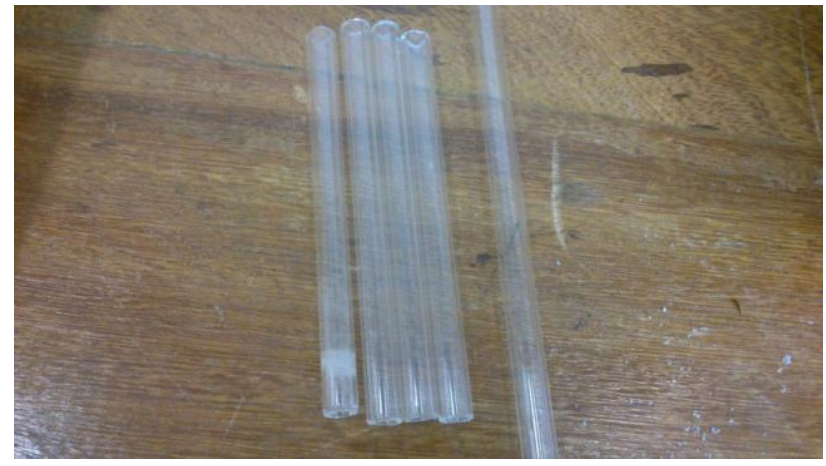

Figura 1 - Coluna de vidro

\subsection{Procedimentos experimentais}

A lama vermelha foi recebida por doação de uma empresa fabricante de alumínio que faz uso do Processo Bayer na sua linha de produção. Separou-se parte da lama recebida que foi encaminhada para o processo de secagem em estufa à $100^{\circ} \mathrm{C}$, durante 24 horas, conforme Figura 2.

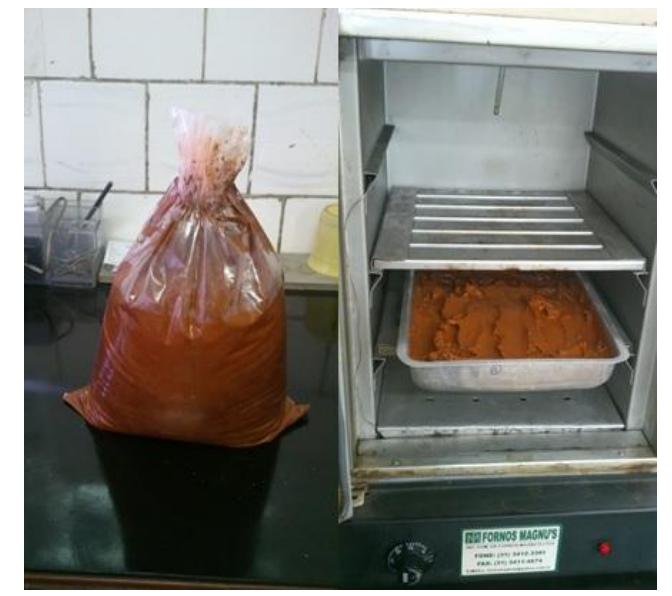

Figura 2 - Recebimento e secagem da lama vermelha

Após secagem, a amostra foi pulverizada em moinho de panelas. Dessa amostra foram pesadas 9 alíquotas de $20 \mathrm{~g}$ cada, sendo que as mesmas foram submetidas a tratamentos distintos, variando volume de $\mathrm{H}_{2} \mathrm{O}_{2}$, tempo de agitação da amostra na solução de peróxido de hidrogênio, temperatura de calcinação e $\mathrm{pH}$ final da amostra.

Após pesagem dos $20 \mathrm{~g}$ da amostra, foi adicionado o volume específico de $\mathrm{H}_{2} \mathrm{O}_{2}$ e feita agitação em tempo pré-determinado. Em seguida a lama foi filtrada em papel de filtro faixa preta, seguindo para o tratamento térmico em mufla por 1 hora. A amostra passou então pela correção do $\mathrm{pH}$, utilizando-se solução de $\mathrm{HCl}$ 1:1 e de $\mathrm{NaOH} 0,1$ mol.L $\mathrm{L}^{-1}$ para correção inversa. Foi feita nova filtração a vácuo e posteriormente a amostra passou por secagem em estufa a $100^{\circ} \mathrm{C}$. Tais etapas estão demostradas nas Figuras 3 e 4 a seguir. 


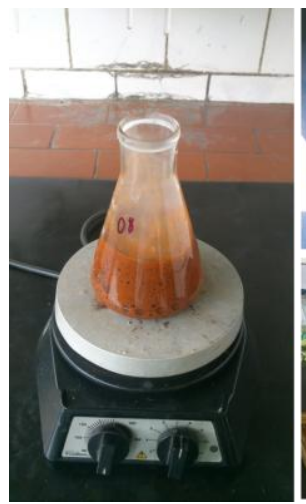

Figura 3 - Etapas do tratamento da lama vermelha (Tratamento Químico)

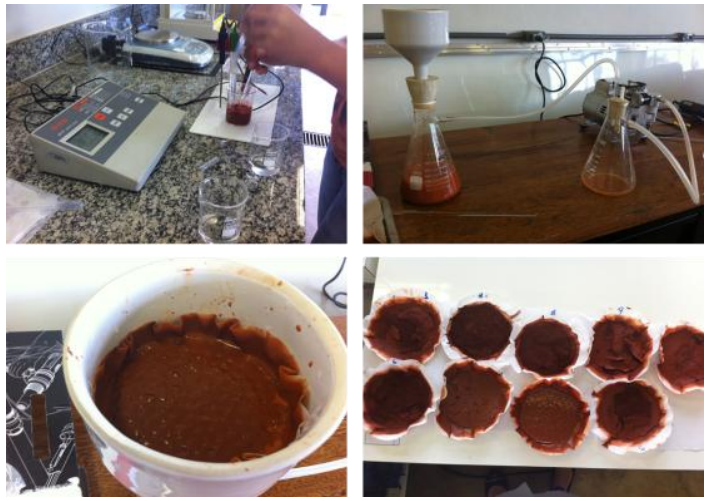

Figura 4 - Etapas do tratamento da lama vermelha (correção $\mathrm{pH}$, filtração a vácuo)

Para facilitar o tratamento estatístico dos dados, para cada variável foram determinados três níveis, especificados a seguir:

Tabela 1 - Níveis das variáveis de tratamentos térmico e químico da lama vermelha

\begin{tabular}{ccccc}
\hline Nível & Temperatura $\left({ }^{\circ} \mathrm{C}\right)$ & $\mathrm{pH}$ & Volume $\mathrm{H}_{2} \mathrm{O}_{2}(\mathrm{~mL})$ & Agitação (minutos) \\
\hline 1 & 500 & 3 & 20 & 30 \\
2 & 400 & 4 & 40 & 60 \\
3 & ambiente & 5 & 60 & 120 \\
\hline
\end{tabular}

Através do software Statistica os níveis foram distribuídos para cada amostra, gerando a Tabela 2 a seguir:

Tabela 2 - Distribuição das variáveis em níveis estatísticos.

\begin{tabular}{ccccc}
\hline Amostra & Temperatura $\left({ }^{\circ} \mathrm{C}\right)$ & $\mathrm{pH}$ & Volume $\mathrm{H}_{2} \mathrm{O}_{2}(\mathrm{~mL})$ & Agitação (minutos) \\
\hline 1 & 500 & 3 & 20 & 30 \\
2 & 500 & 4 & 40 & 60 \\
3 & 500 & 5 & 60 & 120 \\
4 & 400 & 3 & 40 & 120 \\
5 & 400 & 4 & 60 & 30 \\
6 & 400 & 5 & 20 & 60 \\
7 & ambiente & 3 & 60 & 60 \\
8 & ambiente & 4 & 20 & 120 \\
9 & ambiente & 5 & 40 & 30 \\
\hline
\end{tabular}


Após cada amostra passar pelo tratamento especificado a lama foi colocada no tubo descrito anteriormente. Em seguida o tubo foi acoplado em um tubo plástico para coleta do efluente tratado e adicionado água contendo o corante azul de metileno, conforme Figura 5.

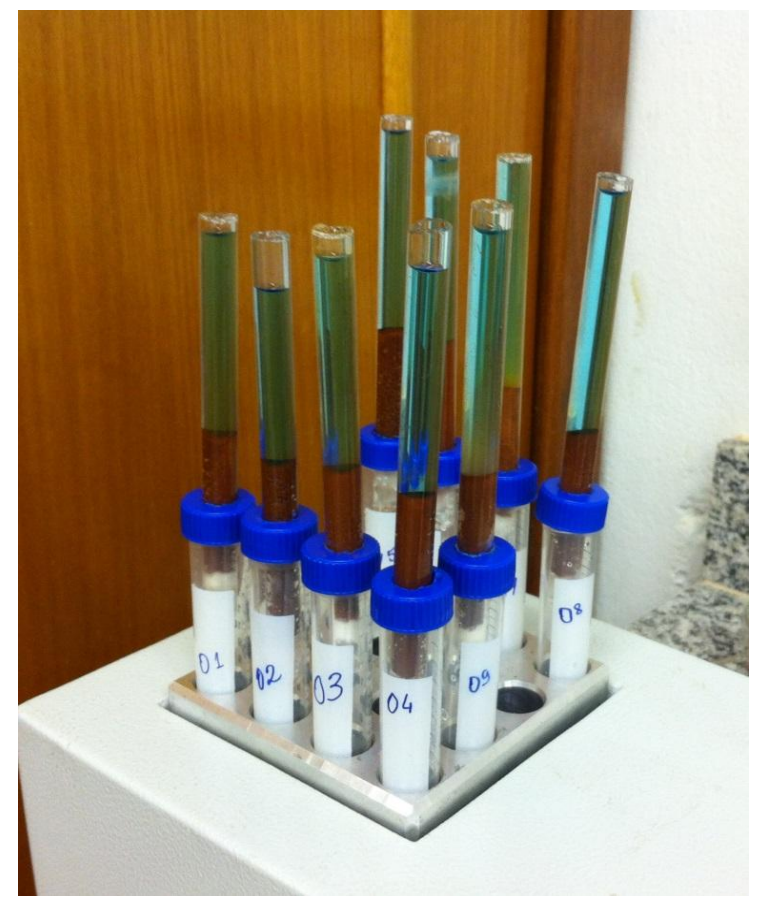

Figura 5 - Aparato experimental

Com intuito de simular o tratamento de um efluente têxtil, foi usado uma solução de concentração inicial de 0,1 g.L $\mathrm{L}^{-1}$ de azul de metileno.

A amostra contendo o corante azul de metileno foi submetida a espectrofotometria de UV visível antes e após passagem pela coluna de lama vermelha.

\section{RESULTADOS E DISCUSSÃO}

O procedimento experimental foi realizado conforme descrição no Item 3.2. As amostras do efluente que percolou a coluna de lama vermelha foram coletadas após um período de 20 horas e então analisadas no espectrofotômetro de UV visível em comprimento de onda de $590 \mathrm{~nm}$, obtendo-se os resultados de absorbância descritos na Tabela 3. A amostra inicial de concentração 0,1 g.L $\mathrm{L}^{-1}$ apresentou absorbância de 0,389. A partir desse valor pode-se fazer a variação entre a absorbância inicial e final de cada amostra e também a porcentagem de remoção do corante da amostra, uma vez, que a concentração é diretamente proporcional ao valor da absorbância. 
Tabela 3 - Dados de absorbância das amostras após tratamento com a lama vermelha

\begin{tabular}{cccc}
\hline Amostra & Absorbância & Variação & Remoção (\%) \\
\hline 1 & 0,006 & 0,383 & 98,46 \\
2 & 0,006 & 0,383 & 98,46 \\
3 & 0,009 & 0,38 & 97,69 \\
4 & 0,010 & 0,379 & 97,43 \\
5 & 0,011 & 0,378 & 97,17 \\
6 & 0,010 & 0,379 & 97,43 \\
7 & 0,009 & 0,38 & 97,69 \\
8 & 0,007 & 0,382 & 98,20 \\
9 & 0,013 & 0,376 & 96,66 \\
\hline
\end{tabular}

Utilizando o software Statistica, fez-se o tratamento dos dados, encontrando-se as melhores condições de tratamento da lama vermelha. Os gráficos apresentados a seguir foram todos gerados por meio desse software.

Uma das grandes vantagens da condução de experimentos usando o método Taguchi é a previsão da combinação que fornece uma resposta ótima de cada fator de controle, desde que não haja forte interação entre os efeitos dos fatores de controle sobre as respostas (Pessoa, et al, 2010). A combinação ótima para os resultados desse experimento é apresentada na Figura 6 a seguir.

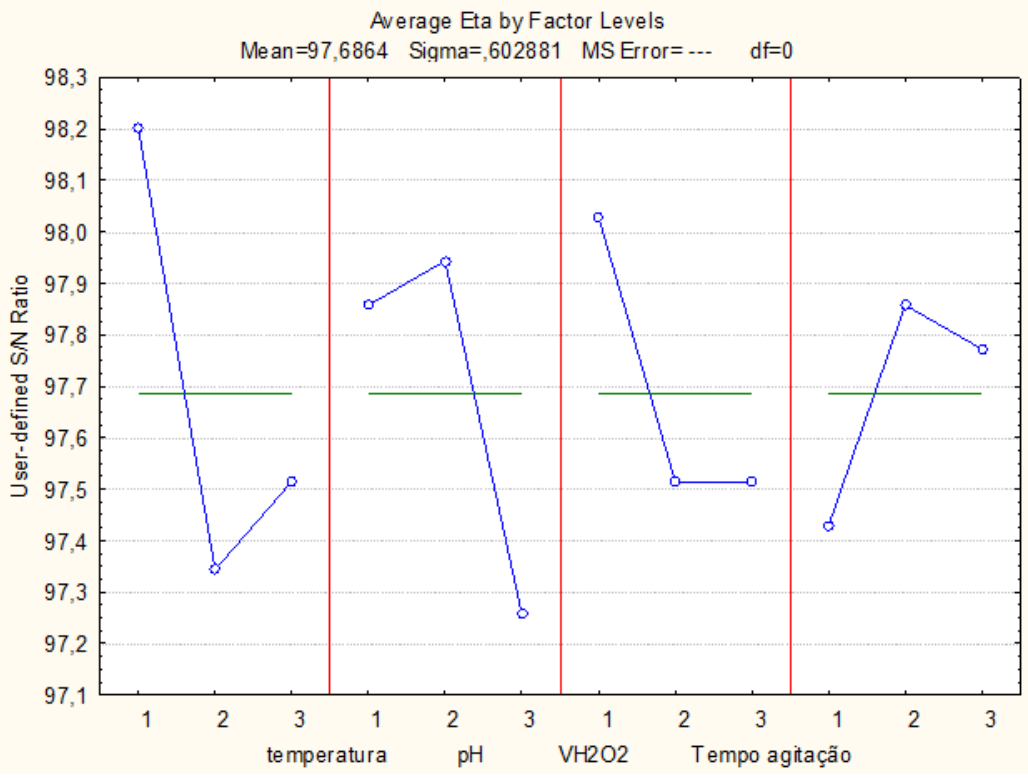

Figura 6 - Gráfico sinal ruído versus níveis 


\section{9 a 22 de outubro de 2014 \\ Florianópolis/SC}

Conforme observa-se no gráfico acima a melhor condição de tratamento da lama vermelha seria na temperatura nível $1\left(500^{\circ} \mathrm{C}\right)$, pH nível 2 (4), volume de peróxido de hidrogênio nível $1(20 \mathrm{~mL})$ e tempo de agitação nível 2 (60 minutos). A seguir é apresentado detalhadamente a melhor condição para cada variável e seus níveis.

De acordo com Souza (2009) e Jesus e Urban (2010) que tem pesquisas realizadas nessa mesma linha, a temperatura de $500^{\circ} \mathrm{C}$ para ativação da lama vermelha é mais favorável para remoção do corante em solução aquosa, o que é comprovado pelo gráfico acima.

Como se pode verificar o nível 2, referente ao $\mathrm{pH}$ igual 4,0 é o que apresenta maior eficiência na remoção do corante azul de metileno. Em meio ácido os íons ferrosos $\left(\mathrm{Fe}^{2+}\right)$ servem de catalisadores para decomposição do peróxido de hidrogênio $\left(\mathrm{H}_{2} \mathrm{O}_{2}\right)$, gerando radical hidroxila, extremamente reativo, capaz de oxidar efetivamente grande parte dos compostos presentes no efluente. Pode-se notar que em decorrência disso há uma diferença irrisória entre a eficiência entre o pH 3 e 4. Aumentando-se o pH do meio, contribui-se para a precipitação de íons $\mathrm{Fe}^{3+}$, tornando a lama mais viscosa e diminuindo a eficiência do tratamento, como demonstrado no gráfico acima onde em pH 5 houve menor remoção do corante.

Segundo Souza (2010), os íons ferrosos $\left(\mathrm{Fe}^{2+}\right)$ servem de catalisadores para decomposição do peróxido de hidrogênio $\left(\mathrm{H}_{2} \mathrm{O}_{2}\right)$, em meio ácido, gerando radical hidroxila, extremamente reativo, capaz de oxidar efetivamente grande parte da matéria orgânica presente em efluentes em uma demanda de tempo de apenas alguns minutos. Percebe-se que o volume de $20 \mathrm{~mL}$ foi suficiente para geração dos íons hidroxila em presença dos íons ferrosos contidos na amostra. Pode-se inferir, que com os demais volumes houve excesso de peróxido de hidrogênio no meio, causando interferências no processo oxidativo do corante presente na amostra.

Verifica-se que maiores tempos de agitação proporcionam uma melhor reação entre os íons ferrosos do meio e o peróxido de hidrogênio adicionado. Percebe-se que após uma hora de agitação essa reação se estabiliza, não necessitando de tempos superiores a esse.

\section{CONCLUSÃO}

A partir dos resultados dos experimentos realizados foi observado que a metodologia e o planejamento do tratamento empregado nas amostras de lama vermelha foi uma ferramenta muito eficaz, sendo possível alcançar as condições otimizadas com a confiabilidade na resposta obtida, demonstrado pela relação reposta e sinal ruído.

Pôde-se determinar o melhor tratamento para a ativação da lama vermelha, considerando as variáveis temperatura, $\mathrm{pH}$, volume de peróxido de hidrogênio e tempo de agitação, obtendo-se valores ótimos em função da remoção do corante e da minimização de custos.

A calcinação da amostra a temperatura de $500^{\circ} \mathrm{C}$, propiciou uma remoção aproximada de $98,2 \%$ do corante presente na amostra, apresentando um resultado muito eficiente. $\mathrm{O} \mathrm{pH}$ em 4, tornou 
possível a remoção de aproximadamente $97,9 \%$ do resíduo, enquanto o volume de 20 mL de peróxido de hidrogênio obteve remoção de $98,1 \%$ e com tempo de agitação de 1 hora a remoção foi em torno de $97,8 \%$.

Baseado nos resultados obtidos conclui-se que a ativação da lama vermelha através de tratamentos térmico e químico é uma alternativa eficaz para a redução dos rejeitos dos Processos Bayer que são encaminhados para barragens de contenção, utilizando tal resíduo após ativação no tratamento dos efluentes da indústria têxtil. Tornando esse processo uma alternativa ambientalmente correta, uma vez que trata-se de rejeitos de dois processos distintos.

\section{REFERÊNCIAS}

FIGUEIREDO, B. R., 2000. Minérios e Ambiente. Unicamp, Campinas.

\section{MÁRTIRES, R. A. C. Economia Mineral do Brasil 2009.} https://sistemas.dnpm.gov.br/publicacao/mostra_imagem.asp?IDBancoArquivoArquivo=3980 Acesso em 08 de janeiro de 2014

PESSOA, A. R. P., MIRANDA, H.C., FARIAS, J. P., AGUIAR, W. M., FILHO, F. A. Seleção de Parametros Atraves do Método de Taguchi para Soldagem de Revestimentos com Liga de Níquel pelo Processo MIG/MAG. Soldag. Insp. Vol 15, p. 317-324, São Paulo, 2010.

SOUZA, S.J.O., LOBO, T.M., SABINO, A.L.O.; OLIVEIRA, S.B.; COSTA, O.S. Decomposição dos antirretrovirais lamivudina e zidovudina pelo processo fotofenton assistido no efluente de indústria farmoquímica. Revista Processos Químicos, v.4, n.7, p.59-67, 2010.

WANG, S; ANG, H.M; TADE, M.O. Novel applications of red mud as coagulant, adsorbent and catalyst for environmentally benign processes. Chemosphere 72, 1621-1635, 2008. 